\title{
Development of an Improved Pedal Powered Hacksaw
}

\section{Machine}

\author{
Mogaji Pius Bamidele \\ Department of Mechanical Engineering, School of Engineering and Engineering Technology, Federal University of Technology, \\ PMB 704, Akure, Ondo State, Nigeria
}

\begin{abstract}
Pedal powered hacksaw machine which can be used for small-scale industrial applications and Household needs in which no specific input energy or power is needed in both rural and urban area where there no adequate supply of electricity was developed. Machine consists of a sprocket arrangement, the crank and slider mechanism, the chain drive. In the mechanism, chain drive is directly connected to the hacksaw for cutting of woods, plastics and metals. The material selection was carried out which is mainly mild steel and angle iron to carry the weight of the machine. Performance evaluation was carried out on the machine to ascertain its effectiveness. A Polyvinylchloride (PVC) pipe of diameter $30 \mathrm{~mm}$ and a thickness of $3 \mathrm{~mm}$ was cut at various trials, the number of strokes and time used in cutting the pipe completely were recorded. Time taken to achieve several cutting depth on a wood of thickness $45 \mathrm{~mm}$ were recorded. Several shaft diameters made of hardened steel were cut using the pedal powered hacksaw and the various time spent during the cutting processes were recorded which shown high efficiency of the machine developed. The cost of production was 44,000 Naira (approximately 232 US Dollars).
\end{abstract}

Key words: Development, hacksaw, improved, pedal, powered.

\section{Introduction}

Investigate carried out by [1] reveals that an individual can generate four times more power $(1 / 4$ HP) by pedalling than by hand-cranking. At the rate of $1 / 4 \mathrm{HP}$, continuous pedalling can be served for only short periods, approximately 10 minutes. However, pedalling at half this power (1/8 HP) can be sustained for close to 60 minutes but power capability can depend upon age. As a consequence of the brainstorming exercise, it was apparent that the primary function of pedal power one specific product was particularly useful: the bicycle. Many devices can be run right away with mechanical energy.

Author [2] said pedal power enables a person to drive devices at the same rate as that achieved by hand cranking, but with far less effort and fatigue. Pedal power also lets one drive devices at a faster rate than before (e.g., winnower), or power devices that require

Corresponding author: Mogaji Pius Bamidele, Ph.D., research field: production. too much for hand-cranking (e.g., thresher). Bicycles can be adapted to drive such devices, but the net result is inefficient. It is cheaper in initial and maintenance costs to use a properly designed and constructed decapod. A decapod is a portable pedalling apparatus that consists of a stand, saddle, handlebar, pedals and sprocket wheel. The name comes from the Greek words for "power" and "foot". Decapod power varies according to the size and fitness of the operator and the length of time spent pedalling [3].

A saw is a tool that uses a hard blade or wire with an abrasive edge to cut through softer materials. The cutting edge of a saw is either a serrated blade or an abrasive. A saw may be worked by hand, or powered by steam, water, electric or other power. An abrasive saw uses an abrasive disc or band for cutting, rather than a serrated blade [4].

\subsection{Machine Description}

The main components of the machine fall into three subsystems: the energy unit, the transmission unit, and 
the cutting unit. The energy unit is a unit of pedal crank arrangement to manually power the machine. The transmission unit is a unit of chain drive transmission mechanism which involves the chain running over a pair of sprockets [5]. This unit also includes the rotating disc directly linked to a smaller sprocket, connecting rod and slider rod. The cutting unit consists of hacksaw and the vice.

The cycle frame is fixed with the base mild steel by the process of welding. The chain sprocket is connected to the cycle frame and it is connected to the pedals. The one end of the chain is connected to the big sprocket and the other end is connected to the small sprocket which is held in a chain hub. The other end of the hub is fixed with the small chain sprocket. From the other end of the hub another chain is connected to the sprocket and other end is connected to another small sprocket which is held with the circular rod and bearing setup. The circular rod is inserted into the bearing and is welded with the sprocket at one end and with rotating disc at the other end. The connecting rod is connected to the rotating disc at one end and to the hacksaw at the other end. The hacksaw moves in fro motion when the pedal is powered, so as the rotating disc rotates as affirm by [6]. The pipe vice is fixed at the end to hold the work piece tightly in a straight position. As the pedal is powered by the human energy, the chain and rotates which makes the hacksaw blade to move in one and fro motion. When the hacksaw moves, the work-piece metal will be cut into a desired shape and the weight holder is fixed above the hacksaw to make the hacksaw blade to move. The isometric view of the pedal powered hacksaw is shown in Fig. 1.

In Fig. 1, the following parts are shown: 1-bearing, 2-chain drive, 3-connecting rod, 4-frame, 5-hacksaw, 6-handle, 7-handle adjuster, 8-pedal, 10-rotating disc, 11-seat, 12-seat adjuster, 13-slider rod, 14-sprocket, 15 -vice.

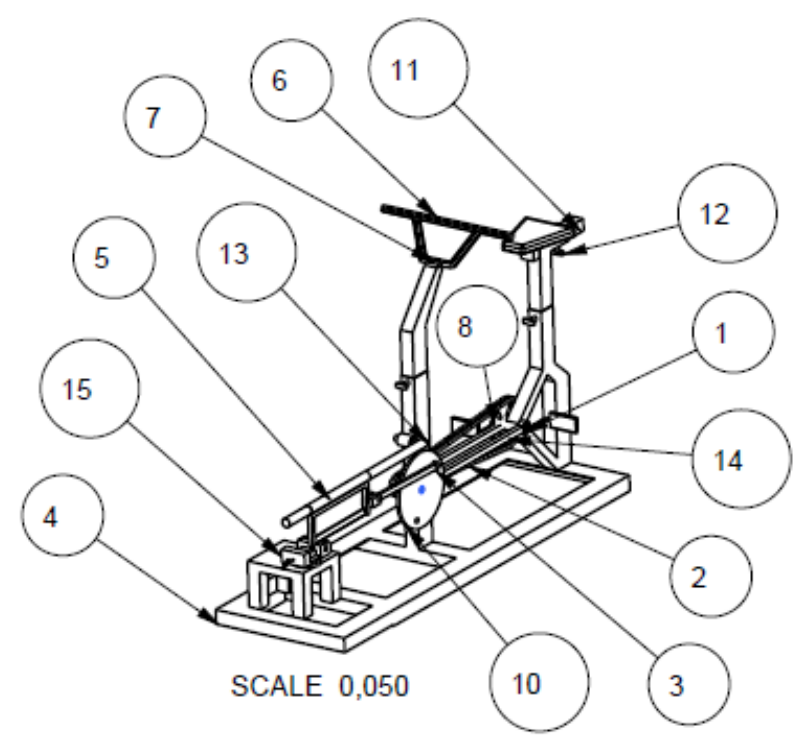

Fig. 1 Isometric view of the pedal powered hacksaw.

\section{Materials}

\subsection{Pedal Crank}

The two pedals are arranged to form a couple through a pedal shaft. In operation, the pedals and their shaft are stressed due to weight of the operator as he uses his feet and leg to rotate the pedal around the crank axel. Therefore, in order to safeguard against failure, the diameter of shaft is determined from the equation [7] as:

$$
d_{p}=\sqrt{\frac{8 F}{\pi \tau}}
$$

where, $d_{p}$ is the diameter of pedal shaft, $F$ is the maximum force selected which an operator may use in pedalling, and $\tau$ is the torsional shear. Having: $F=6$ $\mathrm{kN}, \tau=60 \mathrm{~N} / \mathrm{mm}^{2}, \mathrm{~d}_{\mathrm{p}}=15.96 \mathrm{~mm}$. However, a mild steel rod of diameter $17 \mathrm{~mm}$ is selected as the pedal shaft.

\subsection{Sprocket Design}

The number of teeth on each sprocket was determined based on the transmission ratio needed between the bigger and smaller sprocket/pinion, using Eq. (2) as: 


$$
i=\frac{z_{2}}{z_{1}}
$$

where, $i$ is the transmission ratio, $\mathrm{z}_{1}$ is the number of teeth on driven sprocket/pinion and $z_{2}$ is the number of teeth on driving sprocket/bigger sprocket. $i$ is determined as 2.25 from Table 1 (Jayakumar 2012) below:

The corresponding number of teeth on pinion is determined from Table 2 [8] below as $\mathrm{z}_{1}=25$. Therefore, $\mathrm{z}_{2}=56$.

\subsection{Chain Design}

The total length of chain drive was determined using the design equation (Jayakumar 2012, 40) as:

$$
L_{C D}=\left[\frac{2 a}{p}+\frac{z_{1}+z_{2}}{2}+\left(\frac{z_{2}+z_{1}}{2 \pi}\right)^{2} \frac{p}{a}\right] p
$$

where, $L_{C D}$ is the length of chain, $a$ is the centre distance between axes of bigger sprocket and pinion and $p$ is the chain pitch. Taking: $a=520 \mathrm{~mm}$; the range of chain pitch was determined using the relation [8]:

$$
a=[30 \text { to } 50] p
$$

A suitable standard pitch was selected from table, $\mathrm{p}$ $=12.700 \mathrm{~mm}$. Hence; $\mathrm{L}_{\mathrm{CD}}=1,561 \mathrm{~mm}$.

The choice of suitable chain for the design is determined from Table 4 [8]. Therefore, from table, chain R1278 is selected.

\subsection{Bearing Selection}

The pedal shafts at the bigger sprocket and the pinion run through bearings at both ends of each shaft during operation of the machine. The basic load ratings were determined using the equation [7] as:

$$
C_{b}=W_{e}\left[\frac{60 L_{d} N_{d}}{10^{6}}\right]^{\frac{1}{z}}
$$

where, $C_{b}$ is the basic dynamic load rating, $W_{e}$ is the equivalent load, $L_{d}$ is the design life of bearing to serve machine purpose (Khurmi and Gupta 2008), $z$ is a constant for all bearings and $N_{d}$ is revolution per minute of shaft. Given that: $L_{d}$ and $z$ are 8,000 h and 3 respectively for both shaft bearings. For pedal shaft at bigger sprocket; $\left(W_{e}=1,500 \mathrm{~N}, N_{d}=180 \mathrm{rpm}\right) C_{b}=$ $6.63 \mathrm{kN}$. For pinion shaft; $\left(W_{e}=667 \mathrm{~N}, N_{d}=405\right.$ $\mathrm{rpm}), C_{b}=3.86 \mathrm{kN}$. A self-aligning ball bearing number 203 is selected for both sprockets and a bearing of bore of $17 \mathrm{~mm}$ is selected.

\subsection{Hacksaw-Blade Selection}

The hacksaw blade which performs the cutting during machine operation is expected to cut through work piece between 10-30 $\mathrm{mm}$ thick. Therefore, a high speed steel hex blade of dimension $250 \mathrm{~mm} \times$ $12.5 \mathrm{~mm} \times 0.60 \mathrm{~mm}$ was selected. The total length of hacksaw frame did not exceed $350 \mathrm{~mm}$.

\subsection{Connecting Rod Design}

The connecting rod is one component of the machine which ensures that rotary motion of the rotating disc is received as reciprocating motion by the hacksaw in a crank and slider mechanism. The rod is subjected to compressive force during operation of the machine. The force yielded in the forward movement of the hacksaw against the work-piece may tend to buckle the rod with its neutral axis. Therefore, in order to safeguard against buckling, the cross-sectional area, $\mathrm{A}$ is determined from equation [7] as:

$$
A=\frac{W_{b k}}{\sigma_{c}}\left(\frac{k^{2}+a L_{h}^{2}}{k^{2}}\right)
$$

where, $W_{b k}$ is the buckling load acting on connecting rod, $k$ is the radius of gyration between the rotating disc and the hinged end of the rod, $\sigma_{c}$ is the crushing stress of mild steel material, $a$ is the Rankine's constant and $L_{h}$ is the length of connecting rod. Having: $W_{b k}=50 \mathrm{kN}, k=100 \mathrm{~mm}, \sigma_{c}=275 \mathrm{~N} / \mathrm{mm}^{2}, a$ $=1 / 7500, L_{h}=250 \mathrm{~mm}$, hence, $A=181.97 \mathrm{~mm}^{2}$.

The thickness, $t$ and width, $b$ of the mild steel material used in this design was determined by the relation (Khurmi and Gupta 2008) as: 


$$
t=\sqrt{\frac{12 L_{h}^{2} W_{b k}}{\pi^{2} E A}}
$$

where; $E$ is the modulus of elasticity for mild steel material i.e. $200 \mathrm{kN} / \mathrm{mm}^{2}$. Hence; with an area of $181.97 \mathrm{~mm}^{2}, t=10.22 \mathrm{~mm}$ and $b=17.81 \mathrm{~mm}$.

\subsection{Rotating Disc Design}

The rotating disc is the component driven via the pinion shaft from the rotation of the pinion at the opposite side of the disc. It is the crank which converts this motion to a reciprocating motion needed by the hacksaw. The thickness of the disc equals that of the connecting rod with a diameter of $210 \mathrm{~mm}$.

The pictorial view in Fig. 2 shows the assembly of different components of the developed machine.

\section{Results and Discussion}

\subsection{Testing Procedure}

A PVC pipe of diameter $30 \mathrm{~mm}$ and a thickness of $3 \mathrm{~mm}$ was cut at various trials, the number of strokes and time used in cutting the pipe completely were recorded as shown in Table 1. Time taken to achieve several cutting depth on a wood of thickness $45 \mathrm{~mm}$ were recorded as shown in Table 2. Several shaft diameter made of hardened steel were cut using the pedal powered hacksaw and the various time spent during the cutting processes were recorded as shown in Table 3.

\subsection{Measuring Parameters}

The Fig. 3 shows a plot of cutting speed against time for several cutting trials made on wood.

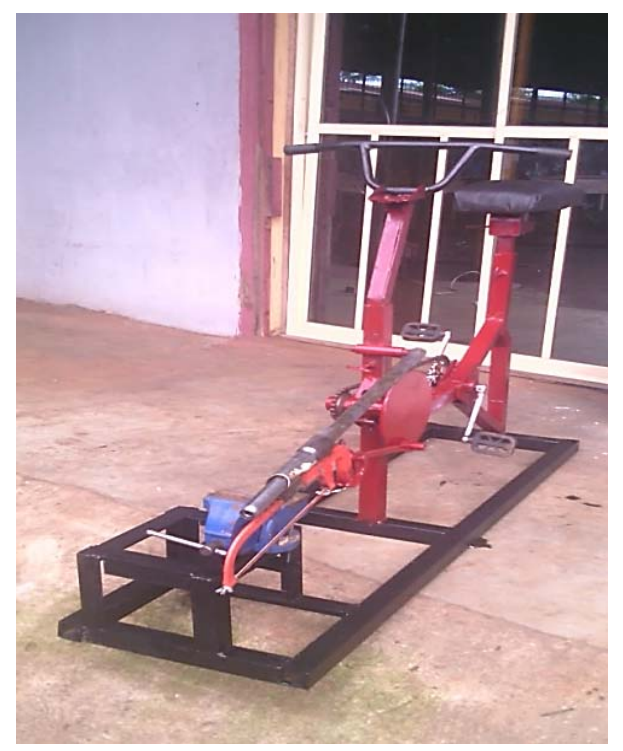

Fig. 2 Improved Pedal Powered Hacksaw Machine Developed.

Table 1 Number of strokes and time taken to completely cut $30 \mathrm{~mm}$ PVC pipe.

\begin{tabular}{lllll}
\hline Parameter & Trial 1 & Trial 2 & Trial 3 & Trial 4 \\
\hline No of strokes & 7 & 8 & 7 & 7 \\
Time (seconds) & 3.83 & 4.80 & 3.44 & 4.86 \\
\hline
\end{tabular}

Table 2 Cutting depth and time taken to achieve various cuts on wood.

\begin{tabular}{llllll}
\hline Parameter & Trial 1 & Trial 2 & Trial 3 & Trial4 & Trial 5 \\
\hline Cutting depth $(\mathrm{mm})$ & 32 & 50 & 70 & 110 & 142 \\
Time $(\mathrm{min})$ & 0.067 & 0.133 & 0.200 & 0.267 & 0.333 \\
\hline
\end{tabular}

Table 3 Shaft diameter and time taken to completely cut hardened steel shafts.

\begin{tabular}{ll}
\hline Shaft diameter $(\mathrm{mm})$ & Time $(\mathrm{min})$ \\
\hline 10 & 0.200 \\
12 & 0.467 \\
15 & 0.967 \\
17 & 1.533 \\
20 & 2.167 \\
25 & 3.017 \\
\hline
\end{tabular}




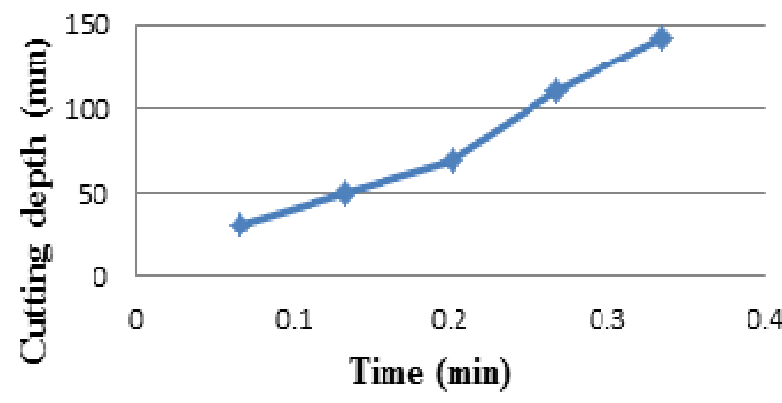

Fig. 3 Graph of cutting speed against time for wood.

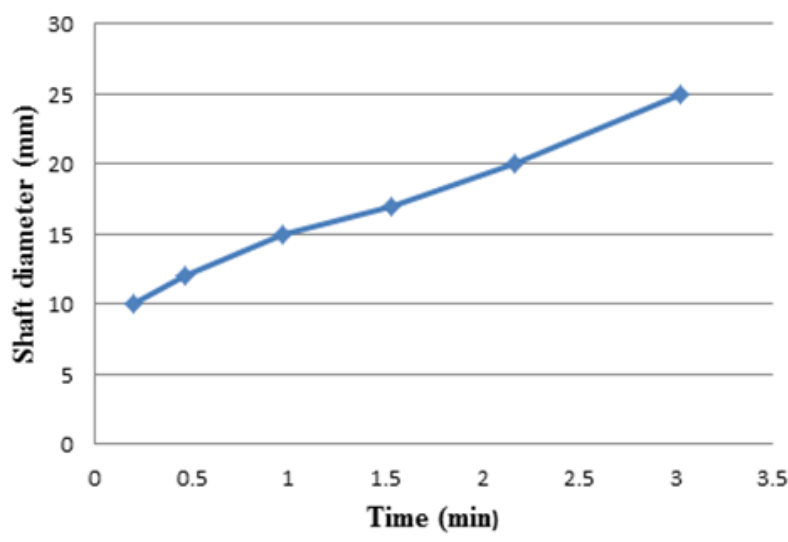

Fig. 4 Graph of shaft diameter against time.

The slope of the graph

$$
\begin{aligned}
& V_{w}=\frac{\text { cutting depth }(\mathrm{mm})}{\text { time }(\min )} \\
& =\frac{142-50}{0.333-0.133} \mathrm{~mm} / \mathrm{min}=460 \mathrm{~mm} / \mathrm{min}
\end{aligned}
$$

The Fig. 4 shows a plot of shaft diameter against time for several cutting trials made on steel.

The slope of the graph:

$$
\begin{aligned}
& V_{S}=\frac{\text { Shaft diameter }(\mathrm{mm})}{\text { time }(\min )} \\
& =\frac{25-10}{3.017-0.2} \mathrm{~mm} / \mathrm{min}=5.32 \mathrm{~mm} / \mathrm{min}
\end{aligned}
$$

The variation in the obtained plot is due to errors in observation and due to power transmission losses.

The results obtained from the design analysis of the component parts of the machine show that the design will function as intended. The values of the slope of the graph in Figs. 4 and 5 respectively represent the cutting speeds for wooden and metallic materials using the pedal powered hacksaw. From these figures also, it was seen that the cutting speed $\left(V_{W}\right)$ of the hacksaw while cutting a wooden material is 86 times the cutting speed $\left(V_{S}\right)$ of the hacksaw while cutting a metal (such as hardened steel and other tough metals). Therefore, it indicates that it takes more time to cut metals than wooden materials. The two values obtained for the cutting speed indicates that the machine is economically okay for small scale industries. From the evaluation processes carried out on PVC pipe, wood and metal, it was seen that the machine is highly efficient.

\section{Conclusions}

The development of the pedal powered hacksaw has been successfully completed and its objectives fully achieved. It is very important to note that design and development of the pedal powered hacksaw was based on the materials locally available. The outcome of the project was successful, as it requires little maintenance and the machine can be operated conveniently by people of different heights since both the seat and handle are adjustable, thus making it ergonomically effective. More so, the machine can be used when there is power outage and in remote areas and there is ease of operation which makes it easy for any individual to operate irrespective of his/her education background as it does not require a training license. The pedal powered hacksaw is not expensive or not too heavy but has the required strength and capacity to operate with little vibration and the machine can cut materials faster than when hand is used for cutting.

\section{References}

[1] Subash, R. A., Meenakshi, C. M., Jayakaran, K. S., Venkateswaran, C., and Sasidharan, R. 2014. "Fabrication of Pedal Powered Hacksaw Using Dual Chain Drive." International Journal of Engineering and Technology 3 (2): 220-3.

[2] Sermaraj, M. 2006. Design and Fabrication of Pedal Operator Reciprocating Pump. New York. McGraw-Hill. 128-30.

[3] Alex, A. 1980. "A Pedal Powered Unit Volunteers in Technical Assistance.” In The Decapod, Maryland, USA. ISBN 0-86619. 
[4] David, G. W. 1986. "Understanding Pedal Power. Volunteers in Technical Assistance.” Technical paper 51, Wilson Boulevard, USA. ISBN: 0-86619.

[5] Alao, S. 1998. Agricultural Engineer's Hand book. New York: McGraw-Hill.

[6] John, S. F., and Stephens, G. 1972. "Engineering Design and Techniques." Macmillan Publisher Ltd. 6: 125-6.

[7] Khurmi, R. S., and Gupta, J. K. 2008. A Textbook of Machine Design (ed). New Delhi: Eurasia Publishing House, 5098-511.

[8] Jayakumar, D. V. 2012. "Design of Transmission Systems." In Lakshmi Publications Pvt Ltd., 4th revised edition. 